\title{
Leber's hereditary optic neuropathy with late disease onset: clinical and molecular characteristics of 20 patients
}

Konstantin Dimitriadis ${ }^{1,7}$, Miriam Leonhardt ${ }^{1,7}$, Patrick Yu-Wai-Man ${ }^{2,3}$, Matthew Anthony Kirkman ${ }^{2}$, Alex Korsten ${ }^{4}$, Irenaeus F De Coo ${ }^{4}$, Patrick Francis Chinnery ${ }^{2,3}$ and Thomas Klopstock ${ }^{1,5,6,7^{*}}$

\begin{abstract}
Background: Leber's hereditary optic neuropathy (LHON) is a mitochondrial disease that typically causes bilateral blindness in young men. Here we describe the clinical and molecular characteristics of 20 patients with disease onset after the age of 50 years (late onset-LHON).

Methods: From a cohort of 251 affected and 277 unaffected LHON carriers, we identified 20 patients with onset of visual loss after the age of 50 years. Using structured questionnaires, data including basic demographic details, age of onset, progression of visual loss and severity as well as exposure to possible environmental triggers including alcohol, smoking and illicit drugs were retrospectively collected. Groups were compared using the Mann-Whitney-U-Test for two independent groups of sampled data.

Results: The proportion of late onset-LHON in our cohort was $8 \%$ (20 patients, 15 males, 5 females). The mtDNA mutations m.11778G > A and m.3460G > A were found in 16 and 4 patients, respectively. Among 89 asymptomatic carriers above the age of 50 years (28 males, 61 females), the mtDNA mutations m.11778G $>A, m .3460 G>A$ and m.14484 T > C were found in 60, 12 and 17 carriers, respectively. Late onset-LHON patients had significantly higher mean cumulative tobacco and alcohol consumption compared with unaffected carriers. However, there was no significant difference between late onset- and typical LHON patients with regard to daily tobacco and weekly alcohol consumption before disease onset.

Conclusion: As already shown for typical LHON, alcohol consumption and smoking are important trigger factors also for the late manifestation. LHON should be considered in the differential diagnosis of subacute blindness even in older patients.
\end{abstract}

Keywords: LHON, Late-onset LHON, Environmental factors

\section{Background}

Leber's hereditary optic neuropathy (LHON) is a mitochondrial disease characterized by acute or subacute visual loss. The vast majority of patients (90\%) carry one of three primary mitochondrial DNA (mtDNA) mutations: m.11778G $>$ A, m.3460G $>$ A or m.14484 T > C [1-3]. The prevalence of the disorder has been estimated

\footnotetext{
* Correspondence: Thomas.Klopstock@med.uni-muenchen.de 'Department of Neurology, Friedrich-Baur-Institute, Ludwig-MaximiliansUniversity, Munich, Germany

Full list of author information is available at the end of the article
}

at about 1 in 30,000 whereas the mutation carrier rate is estimated to be 1 in 350 [4-6].

LHON is generally perceived as a disease of young men, reflecting its male preponderance $(80 \%)$ and its peak age of onset between the age of 15 and 30 years. However, cases with late onset of visual loss have been described [7-16].

Both the incomplete penetrance and the male predominance in LHON are not fully explained yet. It is considered as a multifactorial disease with complex interactions between genetic and environmental factors. In a previous study, we demonstrated that heavy smoking is a significant risk factor for disease manifestation [17]. 
Here we present the clinical and molecular characteristics of 20 patients with disease onset after the age of 50 years, and define this group as late onset-LHON.

\section{Subjects and methods}

Our study cohort included 251 affected LHON patients and 277 asymptomatic mutation carriers harbouring one of the three primary mtDNA mutations (m.11778G $>$ A, m.3460G > A or m.14484 T > C). Data were available on demographics, age of onset, progression of visual loss and severity, mutation type, and possible triggering factors for visual loss by using a standardized questionnaire). Data on visual function index (VF-14) scores for 402 subjects were also collected, as published previously $[17,18]$. From this cohort, we identified 20 patients with onset of LHON after the age of 50 years and 89 asymptomatic carriers aged $>50$ years. All subjects were of white Caucasian origin except one Asian individual. The respective Institutional Review Boards (LudwigMaximilians-University, Munich, Germany; Newcastle University, UK; and University Medical Center Rotterdam, The Netherlands) approved the study, and informed consent was obtained from each participant.

Data on possible environmental triggers like alcohol, smoking and illicit drugs were retrospectively collected. As described in our previous study [17], cumulative smoking was expressed in terms of 'pack years' (PY, number of cigarettes smoked per day by number of years smoking), whereas the maximum number of cigarettes consumed in a single day was defined as maximum smoking intensity. Similarly, alcohol consumption was expressed in 'drink years' (DY, units of alcohol per week multiplied by the number of years drinking). Maximum consumption of alcohol was defined as the highest number of units (U) of alcohol consumed in one week. In line with the previous study [17], only the consumption prior to the onset of vision loss was considered, both for smoking and alcohol consumption of affected individuals.

SPSSTM v.19 statistical software (Chicago, IL, USA) was used for statistical analysis. The rate of diseased carriers was calculated performing a lifetime distribution function $F(t)=1-S(t)$, were $S$ is the survival function and $t$ time, including censored cases. Groups (carriers with late onsetLHON vs. asymptomatic carriers $>50$ years old vs. LHON patients with onset of symptoms before age of 50) were compared using the Mann-Whitney-U-Test for two independent groups of sampled data.

\section{Results}

20 out of 253 LHON patients were identified with a disease onset $>50$ years $(8 \%)$. Similar to the complete study population, the male to female ratio among the affected 20 late onset patients was 3:1 (15 male and 5 female). The mtDNA mutations m.11778G $>\mathrm{A}$ and $\mathrm{m} .3460 \mathrm{G}>\mathrm{A}$ were found in $16(80 \%)$ and $4(20 \%)$ patients, respectively. Among the 277 asymptomatic mutation carriers, 89 were above age 50 (32\%), 28 being male and $61 \mathrm{fe-}$ male. The mtDNA mutations m.11778G > A, m.3460G > $\mathrm{A}$ and m.14484 $\mathrm{T}>\mathrm{C}$ were found in $60(67.4 \%), 12$ $(13.5 \%)$ and $17(19.1 \%)$ of those asymptomatic carriers, respectively (Table 1). Except for one patient where information about alcohol and tobacco consumption was missing, all the other patients consumed alcohol, and 14 out of 19 patients smoked prior to becoming symptomatic. Four patients indicated to have had higher than average stress levels straight before symptoms started (Table 2).

As already shown in our previous study, the rate of diseased carriers per age was not influenced by the type of primary LHON mutation (lifetime distribution function, $\log \operatorname{rank} \mathrm{p}=0.654$ ). However, the rate of affected male individuals was significantly higher (lifetime distribution function, $\log$ rank $\mathrm{p}<0.000$ ).

Table 1 Characteristics of study population

\begin{tabular}{|c|c|c|c|c|c|c|}
\hline & \multicolumn{2}{|c|}{ Total population } & \multicolumn{2}{|c|}{ Carriers $<50$ Years } & \multicolumn{2}{|c|}{ Carriers $\geq 50$ Years } \\
\hline & Affected & Unaffected & Affected & Unaffected & Affected & Unaffected \\
\hline \multicolumn{7}{|l|}{ Mutation type } \\
\hline m.11778G > A (\%) & $167(66.0)$ & $190(68.6)$ & $118(66.3)$ & $78(66.7)$ & $16(80)$ & $60(67.4)$ \\
\hline m.3460G > A (\%) & $53(20.9)$ & $49(17.7)$ & $31(17.4)$ & $24(20.5)$ & $4(20)$ & $12(13.5)$ \\
\hline m.14484 T>C (\%) & $33(13.0)$ & $38(13.7)$ & $29(16.3)$ & $15(12.7)$ & $0(0)$ & $17(19.1)$ \\
\hline Total & 253 & 277 & 178 & 117 & 20 & 89 \\
\hline \multicolumn{7}{|l|}{ Sex N, (\%) } \\
\hline Male & $194(76.7)$ & $92(33.2)$ & $134(74.9)$ & $32(27.4)$ & $15(75.0)$ & $28(31.5)$ \\
\hline Female & $59(23.3)$ & $185(66.8)$ & $45(25.1)$ & $85(72.6)$ & $5(25.0)$ & $61(68.5)$ \\
\hline Male/Female ratio & 3.3 & 0.5 & 3.0 & 0.37 & 3.0 & 0.46 \\
\hline Mean disease duration & $15.9(16.16)$ & & $10.71(10.47)$ & & $10.5(19.12)$ & \\
\hline VF-14 score (SD) & $25.1(20.8)$ & $97.3(7.1)$ & $25.14(21.18)$ & $98.01(5.22)$ & $18.06(15.27)$ & $96.45(8.91)$ \\
\hline
\end{tabular}


Table 2 Characteristics of late onset-LHON patients

\begin{tabular}{|c|c|c|c|c|c|c|}
\hline & $\begin{array}{l}\text { Age at } \\
\text { onset }\end{array}$ & Sex & $\begin{array}{l}\text { Mutation } \\
\text { type }\end{array}$ & Tobacco* & Alcohol* & Other Triggers \\
\hline 1 & 50 & $\mathrm{~F}$ & 11778 & + & + & - \\
\hline 2 & 50 & $\mathrm{~F}$ & 11778 & + & + & - \\
\hline 3 & 52 & M & 11778 & + & + & - \\
\hline 4 & 53 & M & 11778 & + & + & - \\
\hline 5 & 53 & M & 11778 & + & + & $t^{1}$ \\
\hline 6 & 53 & M & 11778 & + & + & - \\
\hline 7 & 53 & M & 11778 & - & + & $+{ }^{1}$ \\
\hline 8 & 53 & M & 11778 & + & + & - \\
\hline 9 & 55 & M & 11778 & + & + & - \\
\hline 10 & 56 & M & 11778 & + & + & $+{ }^{1}$ \\
\hline 11 & 56 & $\mathrm{~F}$ & 11778 & + & + & - \\
\hline 12 & 57 & M & 11778 & + & + & - \\
\hline 13 & 58 & $\mathrm{~F}$ & 3460 & - & + & - \\
\hline 14 & 61 & M & 11778 & - & + & - \\
\hline 15 & 62 & M & 3460 & + & + & - \\
\hline 16 & 67 & M & 11778 & - & + & - \\
\hline 17 & 74 & $\mathrm{~F}$ & 3460 & - & + & - \\
\hline 18 & 75 & $M$ & 3460 & + & + & - \\
\hline 19 & 76 & $M$ & 11778 & + & + & $+^{1}$ \\
\hline 20 & 75 & $M$ & 11778 & $?$ & $?$ & $?$ \\
\hline
\end{tabular}

*Marked as positive only if consumption was prior to onset of disease.

"Patients indicated increased "stress" as a trigger.

There was no significant difference in the mean duration of disease (time from onset) in patients with late onset-LHON versus patients with onset $<50$ years $(8.9+/-9.02$ years versus $6.79+/-11.32, \mathrm{p}=0.123)$. As expected and in line with our previous study, the mean VF-14 score for affected patients with late onset-LHON was significantly lower than that of unaffected carriers over
50 years old $(18.06+/-15.27$ versus $96.45+/-8.91, \mathrm{p}<$ 0.000). Comparing the VF-14 scores of late onset-LHON patients with symptomatic carriers with onset $<50$ years showed a trend to lower scores for the older patients $(18.06+/-15.27$ versus $25.14+/-21.18, \mathrm{p}=0.144)$. Within the late onset-LHON cohort, patients carrying the m.3460G > A mutation had lower scores than patients carrying the m.11778 G > A mutation, but the result was not significant $(13.89+/-15.43$ versus $19.26+/-15.59$, $\mathrm{p}=0.490)$.

Late onset-LHON patients had significantly higher mean cumulative tobacco consumption compared with unaffected carriers above age 50 years $(23.4+/-27.5$ pack years (PY), versus $9.3+/-13.9 \mathrm{PY}, \mathrm{p}=0.018$ ) and there was a trend to higher mean maximum intensity of smoking (19.33+/-17.25 cigarettes per day versus $11.3+/-14.56$ cigarettes per day, $\mathrm{p}=0.059)$. Concerning alcohol, symptomatic carriers had both a significant higher cumulative consumption and mean maximum intensity of drinking $(137.2+/-108.2 \mathrm{UY}$ versus $62.2+/-87.0 \mathrm{UY}, \mathrm{p}=0.012$ and $99.86+/-255.71 \mathrm{U} /$ week versus $14.61+/-22.06 \mathrm{U} /$ week, $\mathrm{p}<0.000$ ) (Table 3A).

Expectedly, due to longer exposure, life-time cumulative smoking and alcohol consumption were significantly higher in late-onset as compared to typical LHON patients $(23.4+/-27.5$ pack years (PY), versus $4.9+/-8.01$ PY, $\mathrm{p}<0.000 ; 137.2+/-108.2$ UY versus $33.3+/-56.0$ UY, $\mathrm{p}=0.001)$. However, there was no significant difference with regard to daily tobacco and weekly alcohol consumption before disease onset $(13.6+/-14.5$ cigarettes/ day versus $10.3+/-10.4$ cigarettes/day, $\mathrm{p}=0.619$ and 27.8 $+/-29.1 \mathrm{U} /$ week versus $18.1+/-19.5 \mathrm{U} /$ week, $\mathrm{p}=0.284$ ) (Table 3B). This was also true when the analysis was restricted to the 14 late-onset LHON and 89 typical LHON cases that had exposure to both alcohol and tobacco (data not shown).

Table 3 Tobacco and alcohol consumption among late onset-LHON patients, unaffected carriers and "typical" LHON patients

\begin{tabular}{|c|c|c|c|}
\hline \multicolumn{4}{|c|}{ A) Levels of tobacco and alcohol consumption in late onset-LHON patients vs. unaffected carriers over 50 years old } \\
\hline & Affected $\mathrm{N}=\mathbf{2 0}$ & Unaffected $\mathrm{N}=89$ & p value \\
\hline & Mean (SD) & Mean (SD) & \\
\hline Cumulative smoking [PY] & $23.36(27.49)$ & $9.25(13.92)$ & 0.018 \\
\hline Maximum smoking consumption [CPD] & $19.33(17.25)$ & $11.3(14.56)$ & 0.059 \\
\hline Cumulative alcohol [UY] & $137.18(108.17)$ & $62.23(87.04)$ & 0.012 \\
\hline Maximum alcohol consumption [UPW] & $99.86(255.71)$ & $14.61(22.06)$ & 0.000 \\
\hline \multicolumn{4}{|c|}{ B) Tobacco and alcohol consumption in late onset- vs. "typical" LHON patients } \\
\hline & Affected $\mathrm{N}=\mathbf{2 0}>50$ Years & Affected $\mathrm{N}=178<50$ Years & \\
\hline Daily cigarette consumption [CPD] & $13.63(14.48)$ & $10.03(10.43)$ & 0.619 \\
\hline Weekly alcohol consumption [UPW] & $27.78(29.14)$ & 18.09 (19.47) & 0.284 \\
\hline
\end{tabular}

$\mathrm{PY}=$ pack years, $\mathrm{CPD}=$ cigarettes per day, $\mathrm{UY}=$ unit years, $\mathrm{UPW}=$ units per week.

3 A) Cumulative and maximum smoking and alcohol consumption in late onset-LHON patients as compared to unaffected carriers over 50 years B) daily cigarette and alcohol consumption before disease onset in late onset- as compared to 'typical' LHON patients. 


\section{Discussion}

Although most affected individuals with LHON lose vision in the second or third decade of life, the disease is not restricted to young adults. Here we describe a cohort of patients with onset after the age of 50 years (late onset-LHON). Late onset occurred in 20 of 251 LHON patients in our cohort, corresponding to $8 \%$ of patients. While all previously reported cases of late onset in LHON were males, the sex ratio in our study is similar to typical disease in young adults with a male to female ratio of about 3:1. Likewise, we found no difference between typical and late-onset LHON in the distribution of the causative mtDNA mutations and in the severity of the disease as measured using the VF-14 index.

The triggering factors for visual loss in patients harboring one of the typical mutations for LHON are not fully known. Apart from alcohol and smoking, for which a correlation was recently demonstrated [17], many other triggers have been described in single case reports, such as lack of oestrogens, trauma, antiretroviral therapy, HIV, anaemia, cyanide and carbon monoxide intoxication [9,19-23].

Recent studies provided some molecular evidence that estrogens activate the antioxidant enzyme superoxide dismutase 2 and also the mitochondrial biogenesis and thus play a role in maintaining vision in female LHON carriers [24]. In one female with a 11778G > A mutation the natural absence of estrogens at a young age (because of a Perrault syndrome) is discussed as a possible reason for the severe optic atrophy with early onset [25]. While our data do not allow for conclusions on protective effects of estrogens, the similar male/female ratios both in late onset vs. typical LHON patients and in unaffected mutation carriers above vs. below age 50 years argue clearly against post-menopause as a manifestation factor of the disease.

As already shown for typical LHON, alcohol consumption and smoking are important risk factors for disease conversion among patients with late onset-LHON. In the literature, there was one 67-year-old patient who lost his vision after blood loss due to hemorrhage from multiple small bowel arteriovenous malformations and a second one with a long history of HIV and zidovudine treatment prior to onset of disease $[9,19]$. Recently a case series of three late onset-LHON patients with raised intraocular pressure as a potential risk factor triggering visual loss were described [26]. Besides alcohol consumption and smoking, no other secondary factors influencing disease expression were elucidated in late-onset LHON patients reported in this study or in the literature. The finding that life-time cumulative smoking and alcohol consumption are significantly higher in late-onset as compared to younger LHON patients is rather self-evident and does not provide any explanation for the later disease manifestation. More interestingly, the daily tobacco and weekly alcohol consumption before disease onset were not significantly different between late-onset and typical LHON patients. The fact that these pre-manifestation exposure rates to alcohol and tobacco as well as mutation profile and gender distribution are very similar in late onset-LHON and in the younger cases indicates that environmental factors are only partly explaining the variable penetrance of the disease.

\section{Conclusion}

In conclusion, alcohol consumption and smoking are important trigger factors not only for typical LHON but also for late-onset LHON. Moreover, this study shows that LHON should be considered in the differential diagnosis of subacute blindness even in older patients.

\section{Competing interests}

The authors declare that they have no competing interests.

\section{Authors' contributions}

KD: Substantial contributions to conception and design, acquisition of data, analysis and interpretation of data and drafting the manuscript. ML:

Substantial contributions to acquisition of data, analysis and interpretation of data. PYWM: Substantial contributions to acquisition of data, analysis and interpretation of data and revising the manuscript. MAK: Substantial contributions to acquisition of data, analysis and interpretation of data and revising the manuscript. AK: Substantial contributions to acquisition of data, analysis and interpretation of data and revising the manuscript. IdC: Substantial contributions to acquisition of data, analysis and interpretation of data and revising the manuscript. PFC: Substantial contributions to analysis and interpretation of data and revising the manuscript. TK: Substantial contributions to conception and design, analysis and interpretation of data, revising the manuscript and general supervision. All authors read and approved the final manuscript.

\section{Acknowledgements}

This work was supported by a grant from the German Ministry of Education and Research (BMBF, Bonn, Germany) to the German network for mitochondrial disorders (mitoNET, 01GM1113A, to TK),

\section{Author details}

${ }^{1}$ Department of Neurology, Friedrich-Baur-Institute, Ludwig-MaximiliansUniversity, Munich, Germany. ${ }^{2}$ Welcome Trust Centre for Mitochondrial Research, Institute of Genetic Medicine, Newcastle University, Newcastle upon Tyne, UK. ${ }^{3}$ Departments of Neurology and Ophthalmology, Royal Victoria Infirmary, Newcastle upon Tyne, UK. ${ }^{4}$ Department of Neurology, Erasmus Medical Center, University Medical Center Rotterdam, Rotterdam, The Netherlands. ${ }^{5}$ DZNE-German Center for Neurodegenerative Diseases, Munich, Germany. ${ }^{6}$ Munich Cluster for Systems Neurology (SyNergy), 80336 Munich, Germany. ${ }^{7}$ German Network for Mitochondrial Disorders (mitoNET), Munich, Germany.

Received: 14 July 2014 Accepted: 6 October 2014

Published online: 23 October 2014

\section{References}

1. Harding AE, Sweeney MG, Govan GG, Riordan-Eva P: Pedigree analysis in Leber hereditary optic neuropathy families with a pathogenic mtDNA mutation. Am J Hum Genet 1995, 57:77-86.

2. Newman NJ, Biousse V: Hereditary optic neuropathies. Eye (Lond) 2004, 18:1144-1160.

3. Mackey DA, Oostra RJ, Rosenberg T, Nikoskelainen E, Bronte-Stewart J, Poulton J, Harding AE, Govan G, Bolhuis PA, Norby S: Primary pathogenic 
mtDNA mutations in multigeneration pedigrees with Leber hereditary optic neuropathy. Am J Hum Genet 1996, 59:481-485.

4. Man PY, Griffiths PG, Brown DT, Howell N, Turnbull DM, Chinnery PF: The epidemiology of Leber hereditary optic neuropathy in the North East of England. Am J Hum Genet 2003, 72:333-339.

5. Elliott HR, Samuels DC, Eden JA, Relton CL, Chinnery PF: Pathogenic mitochondrial DNA mutations are common in the general population. Am J Hum Genet 2008, 83:254-260.

6. Spruijt L, Kolbach DN, de Coo RF, Plomp AS, Bauer NJ, Smeets HJ, de Die-Smulders CE: Influence of mutation type on clinical expression of Leber hereditary optic neuropathy. Am J Ophthalmol 2006, 141:676-682.

7. Mackey DA, Buttery RG: Leber hereditary optic neuropathy in Australia. Aust N Z J Ophthalmol 1992, 20:177-184.

8. Ajax ET, Kardon R: Late-onset Leber's hereditary optic neuropathy. J Neuroophthalmol 1998, 18:30-31.

9. Goyal S, Riordan-Eva P, Coakes RL: Late onset of Leber's hereditary optic neuropathy precipitated by anaemia. Eye (Lond) 2004, 18:1017-1018.

10. Shah VA, Randhawa S, Mizen T, Lee AG, Foroozan R: You're too old for that. Surv Ophthalmol 2008, 53:403-410.

11. Yu-Wai-Man P, Bateman DE, Hudson G, Griffiths PG, Chinnery PF: Leber hereditary optic neuropathy presenting in a 75-year-old man. J Neuroophthalmol 2008, 28:155.

12. Giraudet S, Lamirel C, Amati-Bonneau P, Reynier P, Bonneau D, Milea D, Cochereau I: Never too old to harbour a young man's disease? $\mathrm{Br} J$ Ophthalmol 2011, 95:887.

13. Decanini-Mancera A, Harrison AR, Lee MS: Another case of leber hereditary optic neuropathy in an octogenarian. J Neuroophthalmol 2009, 29:159-160.

14. Dagi LR, Rizzo JF 3rd, Cestari DM: Leber hereditary optic neuropathy in an octogenarian. J Neuroophthalmol 2008, 28:156

15. Borruat FX, Green WT, Graham EM, Sweeney MG, Morgan-Hughes JA, Sanders MD: Late onset Leber's optic neuropathy: a case confused with ischaemic optic neuropathy. Br J Ophthalmol 1992, 76:571-573.

16. Pfeiffer ML, Hashemi N, Foroozan R, Lee AG: Late-onset Leber hereditary optic neuropathy. Clin Experiment Ophthalmol 2013, 41:690-693.

17. Kirkman MA, Yu-Wai-Man P, Korsten A, Leonhardt M, Dimitriadis K, De Coo IF, Klopstock T, Chinnery PF: Gene-environment interactions in Leber hereditary optic neuropathy. Brain 2009, 132:2317-2326.

18. Kirkman MA, Korsten A, Leonhardt M, Dimitriadis K, De Coo IF, Klopstock T, Griffiths PG, Hudson G, Chinnery PF, Yu-Wai-Man P: Quality of life in patients with leber hereditary optic neuropathy. Invest Ophthalmol Vis Sci 2009, 50:3112-3115.

19. Shaikh S, Ta C, Basham AA, Mansour S: Leber hereditary optic neuropathy associated with antiretroviral therapy for human immunodeficiency virus infection. Am J Ophthalmol 2001, 131:143-145.

20. Riordan-Eva P, Sanders MD, Govan GG, Sweeney MG, Da Costa J, Harding AE: The clinical features of Leber's hereditary optic neuropathy defined by the presence of a pathogenic mitochondrial DNA mutation. Brain 1995, 118(Pt 2):319-337.

21. Berninger TA, von Meyer L, Siess E, Schon O, Goebel FD: Leber's hereditary optic atrophy: further evidence for a defect of cyanide metabolism? Br J Ophthalmol 1989, 73:314-316.

22. Hwang JM, Park HW: Carbon monoxide poisoning as an epigenetic factor for Leber's hereditary optic neuropathy. Korean J Ophthalmol 1996, 10:122-123.

23. DuBois $L G$, Feldon SE: Evidence for a metabolic trigger for Leber's hereditary optic neuropathy. A case report. J Clin Neuroophthalmol 1992, 12:15-16.
24. Giordano C, Montopoli M, Perli E, Orlandi M, Fantin M, Ross-Cisneros FN, Caparrotta L, Martinuzzi A, Ragazzi E, Ghelli A, Sadun AA, d'Amati G, Carelli V: Oestrogens ameliorate mitochondrial dysfunction in Leber's hereditary optic neuropathy. Brain 2011, 134:220-234.

25. Badura-Stronka M, Wawrocka A, Zawieja K, Silska S, Krawczynski MR: Severe manifestation of Leber's hereditary optic neuropathy due to 11778G > A mtDNA mutation in a female with hypoestrogenism due to Perrault syndrome. Mitochondrion 2013, 13:831-834.

26. Thouin A, Griffiths PG, Hudson G, Chinnery PF, Yu-Wai-Man P: Raised intraocular pressure as a potential risk factor for visual loss in Leber Hereditary Optic Neuropathy. PLoS One 2013, 8:e63446.

\section{doi:10.1186/s13023-014-0158-9}

Cite this article as: Dimitriadis et al.: Leber's hereditary optic neuropathy with late disease onset: clinical and molecular characteristics of 20 patients. Orphanet Journal of Rare Diseases 2014 9:158.

\section{Submit your next manuscript to BioMed Central and take full advantage of:}

- Convenient online submission

- Thorough peer review

- No space constraints or color figure charges

- Immediate publication on acceptance

- Inclusion in PubMed, CAS, Scopus and Google Scholar

- Research which is freely available for redistribution

Submit your manuscript at www.biomedcentral.com/submit
Ciomed Central 